\title{
Molecular evidence for the transovarial passage of Babesia gibsoni in Haemaphysalis hystricis (Acari: Ixodidae) ticks from Taiwan: a novel vector for canine babesiosis
}

Frans Jongejan ${ }^{1,2^{*}+}$, Bi-Ling Su ${ }^{3^{*}}$, Hsiang-Ju Yang ${ }^{3}$, Laura Berger ${ }^{1}$, Judith Bevers ${ }^{1}$, Pin-Chen Liu ${ }^{3}$, Jou-Chien Fang ${ }^{3}$, Ya-Wen Cheng ${ }^{3}$, Charlotte Kraakman ${ }^{1}$ and Nadine Plaxton ${ }^{1}$

\begin{abstract}
Background: Babesia gibsoni is the predominant tick-borne protozoan blood parasite affecting dogs throughout the Oriental region. Babesia gibsoni is transmitted by Haemaphysalis longicornis, whereas a similar role has been suggested for Rhipicephalus sanguineus. Haemaphysalis longicornis does not occur in Taiwan, but $R$. sanguineus is widely distributed on dogs. However, clinical cases of babesiosis are mainly restricted to the northern part of the island. The discrepancy between tick distribution and clinical cases stimulated us to investigate the tick species distribution on dogs in northern Taiwan, with the aim to identify the local vector for canine babesiosis.

Methods: Ticks were collected from stray dogs or free ranging pet dogs in northern Taiwan between 2015 and 2017 and, after identification, were tested for the presence of tick-borne Babesia parasites using PCR and reverse line blot (RLB) hybridisation. Moreover, engorged ticks collected from the dogs were incubated at $28^{\circ} \mathrm{C}$ to allow them to oviposit. Their subsequent larval progeny was also examined by PCR/RLB.

Results: A total of 1085 ticks collected from 144 stray dogs at different residential areas consisted of 5 different species: H. hystricis $(n=435)$, R. sanguineus $(n=582)$, $R$. haemaphysaloides $(n=43)$, Amblyomma testudinarium $(n=14)$ and Ixodes ovatus $(n=11)$ were identified. Babesia gibsoni DNA was detected in H. hystricis females $(10.3 \%)$, males $(7.0 \%)$ and in 2. $6 \%$ of the nymphs. One $R$. sanguineus female and one A. testudinarium female tick also carried B. gibsoni DNA. DNA of B. gibsoni was demonstrated in 11 out of 68 (16.2\%) batches of larval ticks derived from engorged $H$. hystricus ticks only. Babesia vogeli DNA was detected only in R. sanguineus females (2.6\%) and males (2.4\%). DNA of B. vogeli was detected in 13 out of 95 (13.7\%) batches of larval ticks derived from engorged R.sanguineus females.

(Continued on next page)
\end{abstract}

\footnotetext{
*Correspondence: F.Jongejan@uu.nl; bilingsu@ntu.edu.tw

${ }^{\dagger}$ Equal contributors

${ }^{1}$ Utrecht Centre for Tick-borne Diseases (UCTD), FAO Reference Centre for

Ticks and Tick-borne Diseases, Faculty of Veterinary Medicine, Utrecht University, Yalelaan 1, 3584, CL, Utrecht, The Netherlands

${ }^{3}$ Institute of Veterinary Clinical Sciences, School of Veterinary Medicine,

National Taiwan University, No.1, Sec. 4 Roosevelt Road, Taipei 106, Taiwan

Full list of author information is available at the end of the article
} 
(Continued from previous page)

Conclusions: Babesia gibsoni DNA was detected in the larval progeny of H. hystricis ticks only, whereas B. vogeli was restricted to the larvae of $R$. sanguineus. This provides evidence for transovarial passage of B. gibsoni in $H$. hystricis and evidence that this tick does act as the local vector for this parasite on dogs in northern Taiwan where most cases of babesiosis are reported. The vectorial capacity of $R$. sanguineus for babesiosis is probably restricted to the transmission of $B$. vogeli only.

Keywords: Taiwan, Babesia gibsoni, B. vogeli, Haemaphysalis hystricis, Rhipicephalus sanguineus, Transovarial transmission

\section{Background}

Babesiosis is an important tick-borne haemoprotozoan disease, which occurs worldwide in a broad range of domestic and wild animal species as well as in humans [1]. Babesiosis in dogs is characterised by a wide range of clinical manifestations from subclinical to severe disease characterized by hemolytic anaemia and disseminated intravascular coagulation [2]. Although differences between breeds of dogs play a role, the main reason for the diverse clinical presentation is the involvement of different Babesia species, which traditionally are divided into two groups according to the relative size of the piroplasm stage within the canine erythrocyte [3]. Babesia canis, Babesia vogeli and Babesia rossi are large Babesia species, whereas Babesia gibsoni and "Babesia vulpes" are characterized by small intra-erythrocytic piroplasms [4-6]. In addition to morphology, significant differences have been reported with respect to their clinical presentation and cross-immunity in dogs [3]. Moreover, there are distinct differences in geographical distribution, serological profile, molecular phylogeny and, last but not least, in their association with particular tick vectors $[3,7,8]$.

Babesia canis is found in the Palaearctic region coinciding with the distribution of its vector tick Dermacentor reticulatus. This tick has been linked to the transmission of B. canis in several original field and laboratory studies conducted in France, Germany and the Netherlands [3, 9-11]. Moreover, Shortt [11] in a historical paper worked with Babesia rossi in Haemaphysalis leachi (now H. elliptica) from South Africa, and not with Babesia canis.

Babesia vogeli has a worldwide distribution coinciding with the cosmopolitan vector tick, Rhipicephalus sanguineus (sensu lato). Experimental evidence that $R$. sanguineus can transmit B. vogeli has been published $[2,3,7]$.

Babesia gibsoni is endemic in Asia, where it is transmitted by Haemaphysalis longicornis ticks between dogs [12]. Outside Asia, B. gibsoni infections are often associated with Pit Bull Terriers and other fighting dogs, whereby it has been hypothesised that an asexual strain of $B$. gibsoni is maintained in the fighting dog population without genetic recombination in the vector tick [4].
In Taiwan, B. gibsoni is the predominant protozoan blood parasite affecting the health of domestic and stray dogs. A five-year retrospective survey among dogs presented at the National Taiwan University between 2008 and 2012 confirmed that B. gibsoni is the most important infectious pathogen causing severe anaemia [13]. Since Taiwan is free of Haemaphysalis longicornis, $R$. sanguineus has been suggested to act as a vector for $B$. gibsoni [14]. However, $R$. sanguineus is widely distributed on dogs, but clinical cases of babesiosis are mainly restricted to the northern part of the island. Here, the tick species distribution on dogs in northern Taiwan was investigated with the aim to identify the local tick vector for canine babesiosis.

\section{Methods}

\section{Tick collection and breeding}

A total of 144 dogs were sampled for ticks at different residential locations for three consecutive years (20152017) (Fig. 1). Ticks were removed using forceps and transported in ventilated tubes to the laboratory for identification. Unfed ticks were stored in $70 \%$ ethanol, whereas engorged females were incubated at $28{ }^{\circ} \mathrm{C}$ and $85 \%$ relative humidity in the dark for production of eggs and hatching of subsequent larvae. All ticks were tested by PCR, including the larval progenies of the engorged females.

\section{PCR amplification and reverse line blot hybridisation}

Ticks were disrupted in $2 \mathrm{ml}$ microcentrifuge tubes containing extraction buffer and stainless steel beads using a Tissuelyser LT (Qiagen Benelux BV, Venlo, The Netherlands). DNA was extracted from the triturated ticks using a DNA extraction kit (Fisher Scientific, Landsmeer, The Netherlands) according to the manufacturer's instructions. Extracted DNA was either directly used or stored at $-20{ }^{\circ} \mathrm{C}$. After DNA extraction, DNA was PCR amplified and tested by using reverse line blot hybridisation (RLB) first applied for differential diagnosis and detection of tick-borne Babesia species by Gubbels [15].

For PCR, the primer pair RLB-F2 (5'-GAC ACA GGG AGG TAG TGA CAA G-3') and RLB-R2 (5'-biotinCTA AGA ATT TCA CCT CTG ACA GT-3') $[16,17])$ (Thermo Fisher Scientific, Breda, The Netherlands) was 


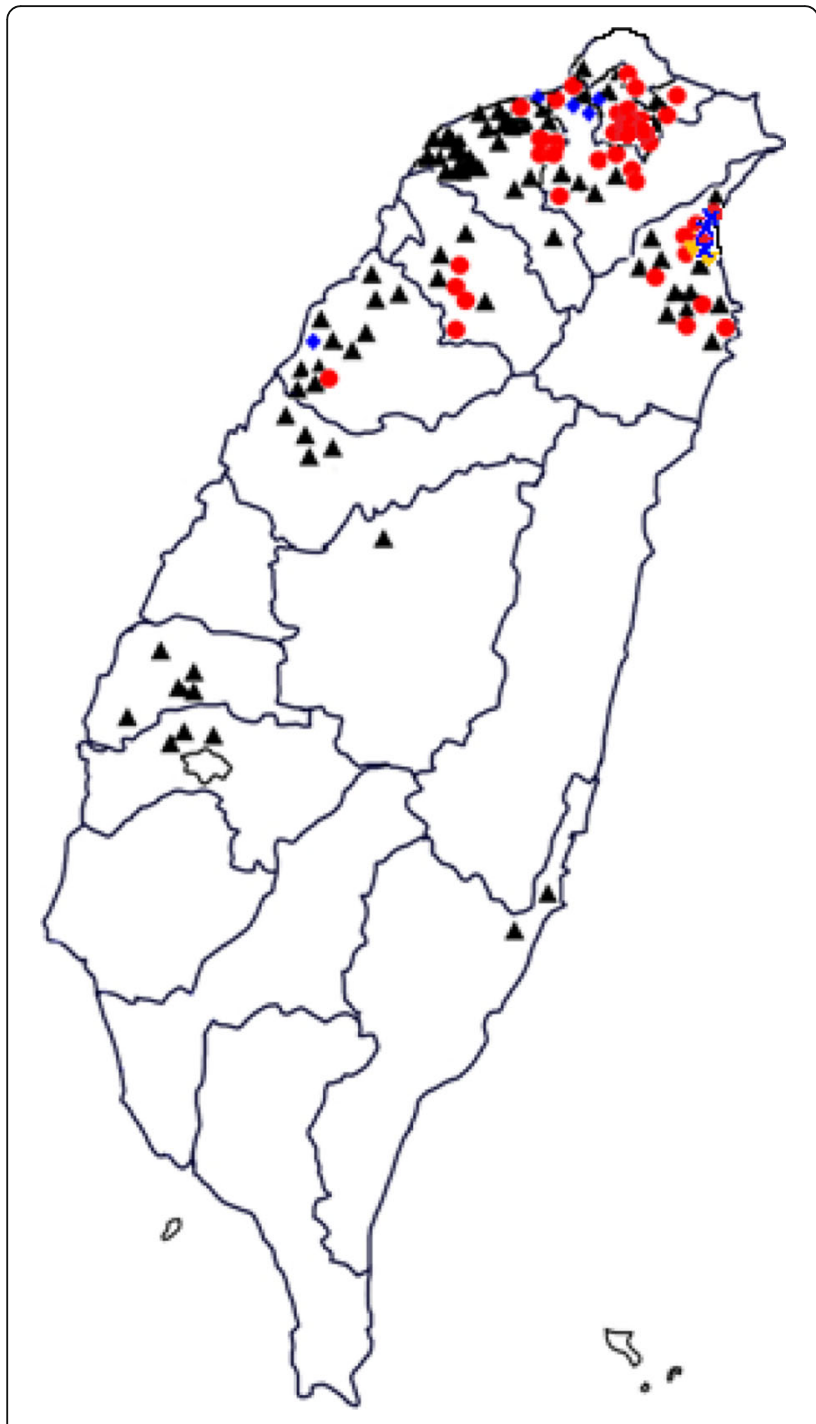

- Haemaphysalis hystricis

- Rhipicephalus sanguineus

Rhipicephalus haemaphysaloides

$\nabla \quad$ Amblyomma testudinarium

$\times \quad$ Ixodes ovatus

Fig. 1 Map of Taiwan with the locations where the different tick species were found on dogs used to amplify the V4 variable region of the $18 \mathrm{~S}$ rRNA gene of Babesia and Theileria species. The length of the PCR amplicon was $460 \mathrm{bp}$. PCR was performed in a total volume of $25 \mu \mathrm{l}$, containing $5 \mu \mathrm{l}$ of a $5 \times$ Phire PCR buffer, $0.5 \mu \mathrm{l}$ of $2 \mathrm{mM}$ dNTP Mixture, $0.5 \mu \mathrm{M}$ each primer, $0.125 \mu \mathrm{l}$ of $5 \mathrm{U} / \mu \mathrm{l}$ Phire Hot Start II polymerase (Thermo Fisher Scientific), $2.5 \mu \mathrm{l}$ of extracted genomic DNA, and double distilled water.

As positive controls, genomic DNA from B. gibsoni as well as from Babesia bovis was used. No template was used as negative control. Strict standard operating procedures were followed to prevent contamination, which included separate rooms for each PCR reaction step and a unidirectional workflow. PCR hoods were equipped with an anti-microbial UV lamp operated at intervals to sterilise the work environment and positive displacement pipettes with barrier tips were used to prevent carryover from one sample to the next. Finally, the entire work surface was sterilized with a bleach dilution between subsequent PCR assays.

Oligonucleotide probes containing an $\mathrm{N}$-terminal $\mathrm{N}$ (trifluoracetamidohexyl-cyanoethyl, N, N-diisopropyl phosphoramidite [TFA])-C6 amino linker was also synthesised by Thermo Fisher Scientific. In addition to $B$. gibsoni and B. vogeli, eight other Babesia species were targeted by these probes (Babesia canis, Babesia rossi, Babesia venatorum, Babesia ovis, Babesia caballi, Babesia bovis and Babesia bigemina)(16). Catch-all Theileria/ Babesia probes were included to capture possible unknown species or variants of species (17).

RLB hybridisation was conducted as previously described [15]. Briefly, a Biodyne $\mathrm{C}$ membrane was activated at room temperature using $16 \%$ (wt/wv) 1-ethyl-3(3-dimethyl-aminopropyl) carbodiimide (EDAC) (Carl Roth GmbH, Karlsruhe, Germany) for $10 \mathrm{~min}$, after which the oligonucleotide probes were covalently linked to the membrane in $0.5 \mathrm{M} \mathrm{NaHCO}_{3}$ in a mini-blotter. The membrane was inactivated in $100 \mathrm{mM} \mathrm{NaOH}$ after washing in $2 \times \mathrm{SSPE} / 0.1 \% \mathrm{SDS}$ at $60{ }^{\circ} \mathrm{C}$ and then stored in $20 \mathrm{mM}$ EDTA, $\mathrm{pH}$ 8.0. For the assays, $10 \mu \mathrm{l}$ of PCR product was added to $150 \mu \mathrm{l}$ of $2 \times \mathrm{SSPE} / 0.1 \% \mathrm{SDS}$ after denaturing at $100{ }^{\circ} \mathrm{C}$ for $10 \mathrm{~min}$, followed by immediate cooling on ice. Denatured PCR products were then hybridised to a pre-prepared Biodyne $\mathrm{C}$ membrane at $42{ }^{\circ} \mathrm{C}$ for $60 \mathrm{~min}$. The membrane was subsequently washed twice in preheated $2 \times \mathrm{SSPE} / 0.5 \% \mathrm{SDS}$ at $50{ }^{\circ} \mathrm{C}$ for $10 \mathrm{~min}$, incubated for $30 \mathrm{~min}$ at $42{ }^{\circ} \mathrm{C}$ in $2 \times \mathrm{SSPE} /$ $0.5 \%$ SDS with $2.5 \mu \mathrm{l}$ of streptavidin-POD conjugate (Roche Diagnostic, Mannhein, Germany), washed twice in preheated $2 \times \mathrm{SSPE} / 0.5 \% \mathrm{SDS}$ at $42{ }^{\circ} \mathrm{C}$ for $10 \mathrm{~min}$, and finally washed twice in $2 \times$ SSPE for 5 min at room temperature. Hybridization detection was performed using chemiluminescence. 


\section{Results}

In total, 1085 ticks were collected from 144 dogs at different residential locations mainly in Northern Taiwan (Fig. 1). Collections were carried out during the spring and summer activity period of the ticks for three consecutive years starting in May 2015 until the end of September 2017. The species composition of the adult ticks recovered from the dogs revealed the presence of five different species. Rhipicephalus sanguineus was the predominant species followed by $H$. hystricis, whereas small numbers of Rhipicephalus haemaphysaloides, Amblyomma testudinarium and Ixodes ovatus were also identified (Table 1).

Haemaphysalis hystricis $(n=435), \quad$ Rhipicephalus sanguineus $(n=582)$, Rhipicephalus haemaphysaloides $(n=43)$, Amblyomma testudinarium $(n=14)$ and Ixodes ovatus $(n=11)$ were tested by PCR/RLB (Tables 1,2$)$. Engorged females of $R$. sanguineus $(n=95)$ and $H$. hystricis $(n=68)$ were allowed to oviposit eggs, and their resulting larval progeny was tested, together with all of the unfed or partially fed tick stages $(n=922)$. Babesia gibsoni DNA was detected in $H$. hystricis females (10.3\%), males $(7.0 \%)$ and in $2.6 \%$ of the nymphal ticks (Table 1). One R. sanguineus female and one $A$. testudinarium female tick were also infected with $B$. gibsoni. There was B. gibsoni DNA in 11 out of 68 (16.2\%) batches of larval ticks produced by engorged $H$. hystricis ticks recovered from the dogs, suggesting transovarial passage (Table 1, Fig. 2). Babesia vogeli DNA was detected in $R$. sanguineus females (2.6\%) and males (2.4\%). There was B. vogeli DNA in 13 out of 95 (13.7\%) batches of larval ticks produced by engorged $R$. sanguineus ticks only (Table 2, Fig. 3).

\section{Discussion}

It is possible that ticks may ingest Babesia with their blood meal and become PCR positive without being able to transmit the parasite. To differentiate between PCRpositive ticks and those that do act as vectors for infectious disease agents, our approach was to allow engorged female ticks to oviposit their eggs and subsequently test their larval progeny. If the parasite is detected within the next generation of ticks, this will provide a strong indication that subsequent transmission can occur.

In this study, it was demonstrated that transovarial passage of $B$. gibsoni occurred in $16.2 \%$ of the larval batches of $H$. hystricis (Table 1, Fig. 2). Likewise, there was the transovarial passage of B. vogeli in $13.7 \%$ of larval batches of $R$. sanguineus ticks (Table 2, Fig. 3). This is strong evidence for a role of $H$. hystricis as a local vector of canine babesiosis, which has not been reported before. Transovarial passage of $B$. vogeli in $R$. sanguineus confirms its involvement in the transmission canine babesiosis.

Haemaphysalis hystricis appears to have a distribution restricted to the northern part of Taiwan (Fig. 1). However, very recently the tick was reported on dogs $(n=9)$ together with many more $R$. sanguineus $(n=306)$ in Nantou County, which is in the central part of Taiwan (Fig. 1) [18]. The finding that $H$. hystricis can act as a vector of canine babesiosis may have regional relevance, since this tick is not restricted in its distribution to Taiwan [19]. Haemaphysalis hystricis Supino, 1897 is the East Asian mountain haemaphysalid, found in India, Sri Lanka, Vietnam, Myanmar, China, Japan, Indonesia, Laos, Thailand, as well as in Taiwan [20]. The tick is prominently listed by Robbins in his synonymic checklist of ticks of Taiwan [21]. Haemaphysalis hystricis appears to be a tick of low to intermediate altitudes from sea level to approximately $7000 \mathrm{ft}$ elevation, which in these latitudes are usually subtropical and available data suggest that this is a forest-inhabiting species. Concerning preferred hosts, the tick has a fairly wide host range from medium size to large carnivores, deer, wild boar, but is also found on domestic dogs and occasionally attacks humans [20]. Other domestic animals and birds are not infested by $H$. hystricis [22].

In addition to the vector role of $H$. hystricis for babesiosis in dogs, a few other pathogens vectored by this tick are worth mentioning. A stercorarian trypanosome species have been isolated from naturally infected $H$. hystricis collected in Kagoshima Prefecture in Japan [23]. Also, in Japan, $H$. hystricus was among ticks collected from dogs in Ehime Prefecture, Shikoku, an endemic area for Japanese spotted fever, suggesting dogs as a host of the vector ticks for Japanese spotted fever

Table 1 Species composition of ticks identified on stray dogs in the North of Taiwan with their respective Babesia gibsoni infection

\begin{tabular}{|c|c|c|c|c|c|}
\hline & \multicolumn{5}{|c|}{ Babesia gibsoni-positive / No. of ticks tested (\%) } \\
\hline & Male & Female & Nymph & Larva & Total \\
\hline Haemaphysalis hystricis & $4 / 57(7.0)$ & 23/223 (10.3) & 2/77 (2.6) & $11 / 68(16.2)$ & $40 / 435(9.2)$ \\
\hline Rhipicephalus sanguineus & $0 / 127(0)$ & $1 / 343(0.3)$ & $0 / 17(0.0)$ & 0/95 (0) & $1 / 582(0.2)$ \\
\hline Rhipicephalus haemaphysaloides & $0 / 1(0)$ & $0 / 42(0)$ & $0 / 0(0.0)$ & $0 / 0(0)$ & $0 / 43(0)$ \\
\hline Amblyomma testudinarium & $0 / 0(0)$ & $1 / 14(7.1)$ & $0 / 0(0.0)$ & $0 / 0(0)$ & $1 / 14(7.1)$ \\
\hline Ixodes ovatus & $0 / 0(0)$ & $0 / 11(0)$ & $0 / 0(0.0)$ & $0 / 0(0)$ & $0 / 11(0)$ \\
\hline
\end{tabular}


Table 2 Species composition of ticks identified on stray dogs in the North of Taiwan with their respective Babesia vogeli infection

\begin{tabular}{|c|c|c|c|c|c|}
\hline & \multicolumn{5}{|c|}{ Babesia vogeli-positive / No. of ticks tested (\%) } \\
\hline & Male & Female & Nymph & Larva & Total \\
\hline Haemaphysalis hystricis & $0 / 57(0)$ & $0 / 223(0)$ & $0 / 77(0)$ & $0 / 68(0)$ & 0/435 (0) \\
\hline Rhipicephalus sanguineus & $3 / 127(2.4)$ & 9/343 (2.6) & $0 / 17(0)$ & 13/95 (13.7) & $21 / 582(3.6)$ \\
\hline Rhipicephalus haemaphysaloides & 0/1 (0) & $0 / 42(0)$ & 0/0 (0) & $0 / 0(0)$ & $0 / 43(0)$ \\
\hline Amblyomma testudinarium & 0/0 (0) & $1 / 14(0)$ & 0/0 (0) & 0/0 (0) & $0 / 14(0)$ \\
\hline Ixodes ovatus & $0 / 0(0)$ & $0 / 11(0)$ & 0/0 (0) & $0 / 0(0)$ & 0/11 (0) \\
\hline
\end{tabular}

control [24]. Finally, a novel Borrelia species was isolated from $H$. hystricis collected from wildlife in an Orang Asli settlement in Selangor, Malaysia [25]. In Taiwan, B. gibsoni appears the only infectious disease agent thus far associated with $H$. hystricis.

In the Oriental region, $H$. hystricis may act as a vector of canine babesiosis in areas outside the distributional range of $H$. longicornis $[19,22]$. The role of $H$. longicornis as a vector for $B$. gibsoni was initially demonstrated by the detection of developmental stages in gut epithelium, hemolymph as well as salivary glands of this tick [26-28]. Subsequently, the role of $H$. longicornis as principle vector of canine babesiosis caused by B. gibsoni

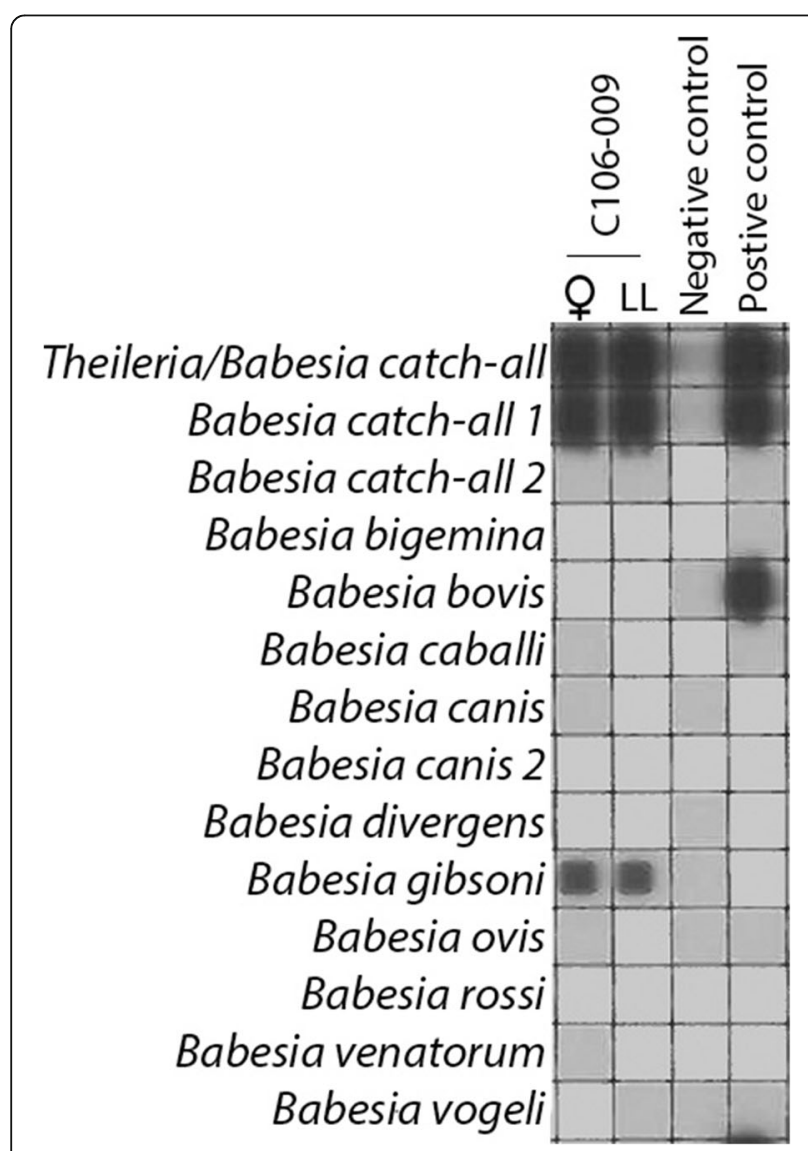

Fig. 2 Reverse line blot wherein transovarial passage of Babesia gibsoni in Haemaphysalis hystricis ticks is demonstrated has been confirmed by many molecular studies, for instance by those conducted in Japan $[29,30]$. Babesia gibsoni can now accurately be quantified in tick tissues using a modified TaqMan probe-based qPCR system that targets parasite DNA in combination with the SYBR Green dye system [31].

On the other species of ticks found in this survey, $R$. sanguineus was the predominant species. Babesia vogeli infections that were found in this tick have been previously reported in Taiwan [32]. Also, this tick has been phylogenetically characterized and was found to be affiliated with the tropical lineage group of the $R$. sanguineus (sensu lato) group [33]. Interestingly, in a similar series of morphological papers as conducted with $H$. longicornis, Higuchi and co-workers reported the development of $B$. gibsoni in the midgut and salivary glands of larval $R$. sanguineus [34, 35], as well as in the midgut of the nymphal stage of this tick [36]. Although transovarial passage of B. gibsoni was demonstrated with a series of

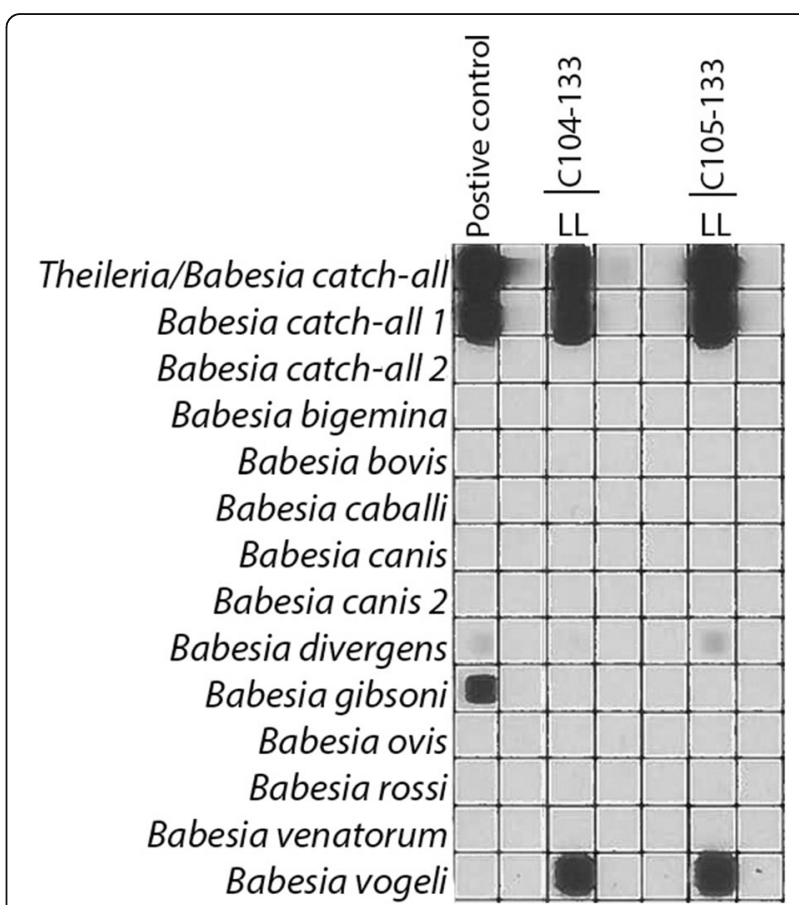

Fig. 3 Reverse line blot wherein transovarial passage of Babesia vogeli in Rhipicephalus sanguineus ticks is demonstrated 
developmental stages culminating in sporozoites in the salivary glands, experimental transmission to dogs was not carried out [26].

Recently, B. gibsoni was for the first time identified in nymphs, male and females of $R$. sanguineus ticks also collected from dogs also in Taiwan [14]. Nearly 1200 ticks collected from veterinary practitioners and pet clinics were examined for Babesia infection, and the infection rates of nymphs, males and female ticks were $2.42 \%, 0.98 \%$ and $1.97 \%$, respectively. Sequence and phylogenetic analysis revealed that these Babesia spp. were $B$. gibsoni and $B$. vogeli. More specifically, two $B a-$ besia strains (GenBank: KU884667 and KU884668) from partial-engorged nymphs were $B$. gibsoni, and the remaining 16 Babesia strains (GenBank: KU884669KU884684) from various stages of the ticks were $B$. vogeli [14]. In our study, one out of 343 female $R$. sanguineus was found infected with B. gibsoni.

Further evidence for a possible vector role of $R$. sanguineus for B. gibsoni has recently been presented in an epidemiological survey of ticks and tick-borne pathogens in pet dogs conducted in China [37]. Ticks $(n=1550)$ were collected from 562 dogs presented at 122 veterinary clinics from 20 major cities in south-eastern China. Among 617 ticks tested by PCR, 8/453 (1.77\%) of R. sanguineus and 5/91 (5.49\%) of H. longicornis were infected with B. gibsoni [37].

There were low numbers of $R$. haemaphysaloides, $A$. testudinarium and $I$. ovatus ticks identified on the dogs in this study. The numbers collected were not sufficient to determine whether they could play any role in the epidemiology of canine babesiosis. Interestingly, in our study, none of the $R$. haemaphysaloides ticks was found infected, whereas $1 / 73$ (1.37\%) of $R$. haemaphysaloides ticks collected in the recent study in China was infected with B. gibsoni [37]. Rhipicephalus haemaphysaloides was previously reported from cattle in Taiwan [38] and on small mammals in different parts of Taiwan [39]. This tick was the predominant tick species and contained a high diversity of Rickettsia spp. [39]. Recently, experimental transmission of Babesia microti by $R$. haemaphysaloides was demonstrated [40].

In our study, one A.testudinarium female contained $B$. gibsoni DNA. Other pathogen relationships have not been reported for this tick, although it was recently genetically analysed after it was identified as a human biting tick species. Finally, Ixodes ovatus has previously been collected from dogs in Taiwan [41] and cats [42]. First detection and molecular identification of Borrelia garinii in Taiwan were from an I. ovatus tick recovered from a stray cat [42]. Our specimens $(n=11)$ were all negative for Babesia infections.

Finally, if one considers the global distribution of B. gibsoni, some epidemiological findings need to be mentioned.
Babesia gibsoni is widespread throughout the Oriental region, for instance in China [43]. However, cases of canine babesiosis caused by $B$. gibsoni have been reported outside the distributional range of its main vector tick, $H$. longicornis, incriminating other ticks for its transmission. The first evidence of $B$. gibsoni (Asian genotype) in dogs in western Europe was reported in two American Pit Bull Terriers [44]. Subsequently, cases have been reported in Croatia, Italy, Serbia, Slovakia, Spain and the UK [2]. A recent large study among pit bull-type fighting dogs in USA revealed that $B$. gibsoni was the predominant infectious disease agent with $39 \%$ of 269 dogs positive [45]. The infection can be transmitted by blood or saliva through bites, and this type of clonal expansion may take place without a sexual cycle through ticks. Furthermore, in Brazil, B. vogeli [46] as well as B. gibsoni [47] have been reported and transmitted by $R$. sanguineus [48]. However, the global distribution of $R$. sanguineus (sensu lato) does not coincide with the distribution of $B$. gibsoni. Maybe there are subpopulations within this diverse phylogenetic group that is unable to transmit. Although $R$. sanguineus has been incriminated, its vectorial ability has not been demonstrated under laboratory conditions [2]. This needs further investigation.

Ultimately, experimental transmission of B. gibsoni by known and putative vector ticks is required in controlled clinical trials, wherein B. gibsoni-positive dogs are simultaneously infested with different tick species for parasite acquisition and separately tested for their capacity to transmit to susceptible dogs. This will provide the final proof of their vectorial capacity.

Finally, it will be interesting to investigate the natural hosts of $B$. gibsoni in Taiwan as recently determined for the causative agent of canine babesiosis in South Africa [49]. Small wildlife mammals such as civet, ferret badger and mongoose, which do occur in Northern Taiwan are possible targets for such an investigation since they are frequently encountered in the same area as where some of the stray dogs were sampled for this study.

\section{Conclusion}

The transovarial passage of B. gibsoni in H. hystricis provides evidence that this tick does act as the local vector for this parasite on dogs, whereas the vectorial capacity of $R$. sanguineus is probably restricted to B. vogeli only.

\section{Abbreviations}

qPCR: Quantitative real-time polymerase chain reaction; RLB: Reverse line blot; SDS: Sodiumdodecylsulfate; SSPE: Sodium chloride-sodium phosphateEDTA; Streptavidine-POD: Streptavidine-peroxidase

\section{Acknowledgements}

Publication of this paper has been sponsored by Bayer Animal Health in the framework of the 13th CVBD World Forum Symposium. 


\section{Availability of data and materials}

The datasets using in this study, as well as the extracted DNA from the collected ticks, are available upon request.

\section{Authors' contributions}

FJ and BLS are equal contributors and conceptualised the study, whereas BLS, HTY, YWC, PCL, SY and JCF conducted the field work consisting of tick collection and identification. JB, CK and NP conducted the PCR/RLB tests. LB was responsible for the breeding of the ticks, supervised and analysed the molecular data. All authors read and approved the final manuscript.

\section{Ethics approval and consent to participate}

Removal of ticks was done according to approved World Organization for Animal Health (OIE) international standards and was carried out with the consent of the dog owners.

\section{Consent for publication}

Not applicable.

\section{Competing interests}

The authors declare that they have no competing interests.

\section{Publisher's Note}

Springer Nature remains neutral with regard to jurisdictional claims in published maps and institutional affiliations.

\section{Author details}

${ }^{1}$ Utrecht Centre for Tick-borne Diseases (UCTD), FAO Reference Centre for Ticks and Tick-borne Diseases, Faculty of Veterinary Medicine, Utrecht University, Yalelaan 1, 3584, CL, Utrecht, The Netherlands. ${ }^{2}$ Vectors and Vector-borne Diseases Research Programme, Department of Veterinary Tropical Diseases, Faculty of Veterinary Science, University of Pretoria, Private Bag X04, Onderstepoort 0110, South Africa. ${ }^{3}$ Institute of Veterinary Clinical Sciences, School of Veterinary Medicine, National Taiwan University, No.1, Sec. 4 Roosevelt Road, Taipei 106, Taiwan.

\section{Received: 24 November 2017 Accepted: 15 February 2018} Published online: 20 March 2018

\section{References}

1. Uilenberg G. Babesia: A historical overview. Vet Parasitol. 2006;138:3-10.

2. Solano-Gallego L, Sainz Á, Roura X, Estrada-Peña A, Miró G. A review of canine babesiosis: the European perspective. Parasit Vectors. 2016;9:336.

3. Uilenberg G, Franssen FFJ, Perié NM, Spanjer AAM. Three groups of Babesia canis distinguished and a proposal for nomenclature. Vet Q. 1989:11:33-40.

4. Irwin PJ. Canine babesiosis: from molecular taxonomy to control. Parasit Vectors. 2009:2:S4.

5. Solano-Gallego L, Baneth G. Babesiosis in dogs and cats-expanding parasitological and clinical spectra. Vet Parasitol. 2011;181:48-60.

6. Baneth G, Florin-Christensen M, Cardoso L, Schnittger L. Reclassification of Theileria annae as Babesia vulpes sp. nov. Parasit Vectors. 2015:8:207.

7. Zahler M, Schein E, Rinder H, Gothe R. Characteristic genotypes discriminate between Babesia canis isolates of differing vector specificity and pathogenicity to dogs. Parasitol Res. 1998;84:544-8.

8. Carret C, Walas F, Carcy B, Grande N, Précigout E, Moubri K, et al. Babesia canis canis, Babesia canis vogeli, Babesia canis rossi: differentiation of the three subspecies by a restriction fragment length polymorphism analysis on amplified small subunit ribosomal RNA genes. J Eukaryot Microbiol. 1999;46:298-303.

9. Mehlhorn H, Schein E, Voigt WP. Light and electron microscopic study on developmental stages of Babesia canis within the gut of the tick Dermacentor reticulatus. J Parasitol. 1980;66:220-8.

10. Martinod S, Brossard M, Moreau Y. Immunity of dogs against Babesia canis, its vector tick Dermacentor reticulatus, and Ixodes ricinus in endemic area. J Parasitol. 1985:71:269-73.

11. Shortt HE. Babesia canis: the life-cycle and laboratory maintenance in its arthropod and mammalian hosts. Int J Parasitol. 1973:3:119-48.

12. Higuchi S, Simomura S, Yoshida H, Hoshi F, Kawamura S, Yasuda Y. Development of Babesia gibsoni in the hemolymph of the vector tick, Haemaphysalis longicornis. J Vet Med Sci. 1991;53:491-3.
13. Liu P-C, Su B-L. Causes of canine anaemia in Taiwan: a five-year retrospective survey. Taiwan Vet J. 2015:41:31-7.

14. Chao L-L, Liao H-T, Ho T-Y, Shih C-M. First detection and molecular identification of Babesia gibsoni from Rhipicephalus sanguineus ticks. Acta Trop. 2017;166:356-62

15. Gubbels JM, de Vos AP, van der Weide M, Viseras J, Schouls LM, de Vries E, Jongejan F. Simultaneous detection of bovine Theileria and Babesia species by reverse line blot hybridization. J Clin Microbiol. 1999;37:1782-9.

16. Nijhof AM, Penzhorn BL, Lynen G, Mollel JO, Morkel P, Bekker CPJ, Jongejan F. Babesia bicornis sp. nov. and Theileria bicornis sp. nov.: tick-borne parasites associated with mortality in the black rhinoceros (Diceros bicornis). J Clin Microbiol. 2003:41:2249-54.

17. Nijhof AM, Pillay V, Steyl J, Prozesky L, Stoltsz WH, Lawrence JA, et al. Molecular characterization of Theileria species associated with mortality in four species of African antelopes. J Clin Microbiol. 2005;43:5907-11.

18. Yuasa Y, Tsai Y-L, Chang C-C, Hsu T-H, Chou C-C. The prevalence of Anaplasma platys and a potential novel Anaplasma species exceed that of Ehrlichia canis in asymptomatic dogs and Rhipicephalus sanguineus in Taiwan. J Vet Med Sci. 2017;79:1494-502.

19. Geevarghese G, Mishra AC. Haemaphysalis ticks of India. Delhi: Elsevier Health Sciences Division; 2011. p. 1-260.

20. Hoogstraal H, Trapido H, Kohls GM. Studies on southeast Asian Haemaphysalis ticks (Ixodoidea, Ixodidae). The identity, distribution, and hosts of H. (Kaiseriana) hystricis Supino. J Parasitol. 1965;51:467.

21. Robbins R. The ticks (Acari: Ixodida: Argasidae, Ixodidae) of Taiwan: synonymic checklist. Proc Entomol Soc Wash. 2005;107:245-53.

22. Guglielmone AA, Robbins RG, Apanaskevich DA, Petney TN, Estrada-Peña A, Horak IG. The hard ticks of the world (Acari: Ixodida: Ixodidae). Dordrecht: Springer Science and Business Media; 2014. p. 1-738.

23. Thekisoe OMM, Honda T, Fujita H, Battsetseg B, Hatta T, Fujusaki K, et al. A trypanosome species isolated from naturally infected Haemaphysalis hystricis ticks in Kagoshima Prefecture, Japan. Parasitology. 2007;134:967.

24. Yamauchi T, Yano S, Yamamoto T, Yamamoto E, Miyamoto T. Ticks (Acari: Ixodidae) from medium-sized to large mammals in Ehime Prefecture, Japan. Exp Appl Acarol. 2013;60:263-70

25. Khoo JJ, Lim FS, Tan KK, Chen FS, Phoon WH, Khor CS, et al. Detection in Malaysia of a Borrelia sp. from Haemaphysalis hystricis (Ixodida: Ixodidae). J Med Entomol. 2017:54:1444-8.

26. Higuchi S, Simomura S, Yoshida H, Hoshi F, Kawamura S, Yasuda Y. Development of Babesia gibsoni in the hemolymph of the vector tick, Haemaphysalis longicornis. J Vet Med Sci. 1991;53(3):491.

27. Higuchi S, Simomura S, Yoshida H, Hoshi F, Kawamura S, Yasuda Y. Development of Babesia gibsoni in the gut epithelium of the tick, Haemaphysalis longicornis. J Vet Med Sci. 1991;53:129-31.

28. Higuchi S, Konno H, Hoshi F, Kawamura S, Yasuda Y. Observations of Babesia gibsoni in the ovary of the tick, Haemaphysalis longicornis. Kitasato Arch Exp Med. 1993:65:153-8.

29. Maeda H, Hatta T, Alim MA, Tsubokawa D, Mikami F, Matsubayashi M, et al. Establishment of a novel tick-Babesia experimental infection model. Sci Rep. 2016;6:37-9.

30. Iwakami $\mathrm{S}$, Ichikawa $\mathrm{Y}$, Inokuma $\mathrm{H}$. Molecular survey of Babesia gibson using Haemaphysalis longicornis collected from dogs and cats in Japan. J Vet Med Sci. 2014;76:1313-6.

31. Hatta T, Matsubayashi M, Miyoshi T, Islam MK, Alim MA, Yamaji K, et al. Quantitative PCR-based parasite burden estimation of Babesia gibsoni in the vector tick, Haemaphysalis longicornis (Acari: Ixodidae), fed on an experimentally infected dog. J Vet Med Sci. 2013;75:1-6.

32. Chao L-L, Yeh S-T, Hsieh C-K, Shih C-M. First detection and molecular identification of Babesia vogeli from Rhipicephalus sanguineus (Acari: Ixodidae) in Taiwan. Exp Appl Acarol. 2016:68:539-51.

33. Chao L-L, Shih C-M. Molecular analysis of Rhipicephalus sanguineus (Acari: Ixodidae), an incriminated vector tick for Babesia vogeli in Taiwan. Exp Appl Acarol. 2016;70:469-81

34. Higuchi S, Izumitani M, Hoshi H, Kawamura S, Yasuda Y. Development of Babesia gibsoni in the midgut of larval tick, Rhipicephalus sanguineus. J Vet Med Sci. 1999:61:689-91.

35. Higuchi S, Fujimori M, Hoshi F, Kawamura S, Yasuda Y. Development of Babesia gibsoni in the salivary glands of the larval tick, Rhipicephalus sanguineus. J Vet Med Sci. 1995;57:117-9. 
36. Higuchi S, Kuroda H, Hoshi H, Kawamura S, Yasuda Y. Development of Babesia gibsoni in the midgut of the Nymphal stage of the tick, Rhipicephalus sanguineus. J Vet Med Sci. 1999;61:697-9.

37. Zhang J, Liu Q, Wang D, Li W, Beugnet F, Zhou J. Epidemiological survey of ticks and tick-borne pathogens in pet dogs in south-eastern China. Parasite. 2017;24:35.

38. Tsai Y-L, Peng-Wen Chan J, Chen S-K, Hsieh J-C, Chuang S-T. Survey of species of ticks infesting cattle in Taiwan. Taiwan Vet J. 2011;37:74-82.

39. Kuo C-C, Shu P-Y, Mu J-J, Lee P-L, Wu Y-W, Chung C-K, Wang H-C. Widespread Rickettsia spp. infections in ticks (Acari: Ixodoidea) in Taiwan. J Med Entomol. 2015;52:1096-102.

40. Li L-H, Zhu D, Zhang C-C, Zhang Y, Zhou X-N. Experimental transmission of Babesia microti by Rhipicephalus haemaphysaloides. Parasit Vectors. 2016;9:231.

41. Jung Wu T, Ju Sun H, Chen Wu Y, Pi HH. Prevalence and risk factors of canine ticks and tick-borne diseases in Taipei, Taiwan. JVCS. 2009;2:3.

42. Chao L-L, Liu L-L, Ho T-Y, Shih C-M. First detection and molecular identification of Borrelia garinii spirochete from Ixodes ovatus tick ectoparasitized on stray cat in Taiwan. PLoS One. 2014;9(10):e110599.

43. He L, Miao X, Hu J, Huang Y, He P, He J, Yu L, Malobi N, Shi L, Zhao J. First molecular detection of Babesia gibsoni in dogs from Wuhan, China. Front Microbiol. 2017:8:1577.

44. Hartelt K, Rieker T, Oehme RM, Brockmann SO, Müller W, Dorn N. First evidence of Babesia gibsoni (Asian genotype) in dogs in western Europe. Vector Borne Zoonotic Dis. 2007;7:163-6.

45. Cannon SH, Levy JK, Kirk SK, Crawford PC, Leutenegger CM, Shuster JJ, et al. Infectious diseases in dogs rescued during dogfighting investigations. Vet J. 2016;211:64-9.

46. Passos LMF, Geiger SM, Ribeiro MFB, Pfister K, Zahler-Rinder M. First molecular detection of Babesia vogeli in dogs from Brazil. Vet Parasitol. 2005;127:81-5.

47. Trapp SM, Messick JB, Vidotto O, Jojima FS, de Morais HAS. Babesia gibsoni genotype Asia in dogs from Brazil. Vet Parasitol. 2006;141:177-80.

48. Dantas-Torres F, Figueredo LA. Canine babesiosis: a Brazilian perspective. Vet Parasitol. 2006:141:197-203.

49. Penzhorn BL, Vorster I, Harrison-White RF, Oosthuizen MC. Black-backed jackals (Canis mesomelas) are natural hosts of Babesia rossi, the virulent causative agent of canine babesiosis in sub-Saharan Africa. Parasit Vectors. 2017;10:124

\section{Submit your next manuscript to BioMed Central and we will help you at every step:}

- We accept pre-submission inquiries

- Our selector tool helps you to find the most relevant journal

- We provide round the clock customer support

- Convenient online submission

- Thorough peer review

- Inclusion in PubMed and all major indexing services

- Maximum visibility for your research

Submit your manuscript at www.biomedcentral.com/submit

) Biomed Central 